Wright State University

CORE Scholar

5-3-2009

\title{
UV Light-Induced Changes to the Surface Conduction in Hydrothermal ZnO
}

B. Claflin

David C. Look

Wright State University - Main Campus, david.look@wright.edu

Follow this and additional works at: https://corescholar.libraries.wright.edu/physics

Part of the Physics Commons

\section{Repository Citation}

Claflin, B., \& Look, D. C. (2009). UV Light-Induced Changes to the Surface Conduction in Hydrothermal ZnO. Journal of Vacuum Science \& Technology B, 27 (3), 1722-1725.

https://corescholar.libraries.wright.edu/physics/6

This Article is brought to you for free and open access by the Physics at CORE Scholar. It has been accepted for inclusion in Physics Faculty Publications by an authorized administrator of CORE Scholar. For more information, please contact library-corescholar@wright.edu. 


\title{
UV light-induced changes to the surface conduction in hydrothermal $\mathrm{ZnO}$
}

\author{
B. Claflin a) and D. C. Look \\ Materials and Manufacturing Directorate, AFRL/RXPS, WPAFB, Ohio 45433 and Semiconductor Research \\ Center, Wright State University, Dayton, Ohio 45435
}

(Received 1 December 2008; accepted 23 March 2009; published 29 May 2009)

\begin{abstract}
High quality, bulk $\mathrm{ZnO}$ crystals grown by Tokyo Denpa using the hydrothermal process typically exhibit a room temperature carrier concentration in the $10^{13}-10^{14} \mathrm{~cm}^{-3}$ range and a low mobility, conductive surface layer, observed at low temperature, with a sheet concentration on the order of $10^{12}-10^{13} \mathrm{~cm}^{-2}$. In the sample discussed here, bulk conduction is controlled by two donor levels at 50 and $400 \mathrm{meV}$ with concentrations of $1.2 \times 10^{16}$ and $1.5 \times 10^{16} \mathrm{~cm}^{-3}$, respectively. Temperature-dependent photo-Hall-effect measurements, using blue/UV light, in vacuum show an increase in the surface sheet carrier density to more than $1 \times 10^{13} \mathrm{~cm}^{-2}$ at low to intermediate temperatures while the two bulk donors continue to dominate the high temperature behavior, up to $400 \mathrm{~K}$. Long-lived persistent photoconductivity (PPC) is observed when the sample is returned to the dark. When the PPC is allowed to fully relax and the sample is exposed to air, there is surprisingly no longer any surface conduction at low temperature, while the two bulk donors remain unaffected. In this state, the $50 \mathrm{meV}$ bulk donor level is observed to control the conduction over five orders of magnitude, down to a carrier concentration of $3.0 \times 10^{8} \mathrm{~cm}^{-3}$. This corresponds to an upper limit for the surface sheet carrier density of $1.6 \times 10^{7} \mathrm{~cm}^{-2}$. This is the lowest surface concentration we have ever observed in any $\mathrm{ZnO}$ sample and demonstrates that blue/UV light irradiation, in vacuum, at moderate temperatures is very effective at cleaning the surface. A subsequent 30 min anneal at $600{ }^{\circ} \mathrm{C}$ in forming gas $\left(5 \% \mathrm{H}_{2}\right.$ in $\left.\mathrm{N}_{2}\right)$ increases the carrier concentration by almost two orders of magnitude. The forming gas anneal produces no changes in the concentrations of the 50 and $400 \mathrm{meV}$ bulk donor levels and no new bulk donors are observed. However, the bulk acceptor concentration decreases from $2 \times 10^{16}$ to $1.2 \times 10^{16} \mathrm{~cm}^{-3}$, most likely as a result of passivation by hydrogen. (c) 2009 American Vacuum Society.
\end{abstract}

[DOI: $10.1116 / 1.3119680]$

\section{INTRODUCTION}

It has long been known $^{1-3}$ that the surface of $\mathrm{ZnO}$ is highly reactive, making it an attractive material for gas sensing applications. ${ }^{4-7}$ Changes in the electrical conductivity by several orders of magnitude have been attributed ${ }^{3,8-11}$ to surface accumulation or depletion layers produced by adsorbed gases such as $\mathrm{H}$ or $\mathrm{O}$ and can be enhanced ${ }^{12,13}$ by UV light irradiation. More recent work ${ }^{14-17}$ has demonstrated that the origin of the surface conductive layer in $\mathrm{ZnO}$ is more complicated than the simple adsorption model and has focused on the development of quantitative tools to analyze the surface donors and acceptors. In this work, we investigate changes in the surface conduction of hydrothermal $\mathrm{ZnO}$ which are produced by light exposure in vacuum and demonstrate that irradiation with UV light can effectively and permanently remove the conductive surface layer that is observed in almost all commercial $\mathrm{ZnO}$ samples.

\section{EXPERIMENTAL DETAILS}

The $\mathrm{ZnO}$ sample used in this study was a $5 \mathrm{~mm}$ $\times 5 \mathrm{~mm} \times 530 \mu \mathrm{m}$ thick, $c$-axis oriented, bulk, hydrothermal plate, supplied by Tokyo Denpa. ${ }^{18}$ A series of

${ }^{a}$ Electronic mail: bruce.claflin@wright.edu temperature-dependent Hall-effect and photo-Hall-effect measurements (described below) was performed using the van der Pauw technique with Ohmic contacts formed by soldering small dots of In onto the corners of the sample. Standard temperature-dependent Hall-effect measurements (in the dark) were conducted on the as-received sample in a LakeShore 7507 apparatus over the range 20-320 K. The sample was maintained in a $\mathrm{He}$ ambient throughout. Temperature-dependent photo-Hall-effect measurements were subsequently performed from 30 to $400 \mathrm{~K}$ in a custombuilt apparatus with the sample in high vacuum. Continuous illumination from a $150 \mathrm{~W}$ halogen lamp, passing through a CS 7-59 blue/UV notch filter with $3.35 \mathrm{eV}$ peak transmission, was focused uniformly on the sample. Following this experiment, standard temperature-dependent Hall-effect measurements were repeated several times over the next few days, with the sample maintained under vacuum, to monitor the slow decay of persistent photoconductivity (PPC). When the PPC had fully relaxed, the sample was returned to the LakeShore apparatus for measurement of temperaturedependent Hall effect in the dark. Finally, the sample was annealed for $30 \mathrm{~min}$ in forming gas $\left(5 \% \mathrm{H}_{2}\right.$ in $\left.\mathrm{N}_{2}\right)$ at $600{ }^{\circ} \mathrm{C}$ in a horizontal furnace, and temperature-dependent Halleffect measurements were performed in the dark using the Lake Shore system. 


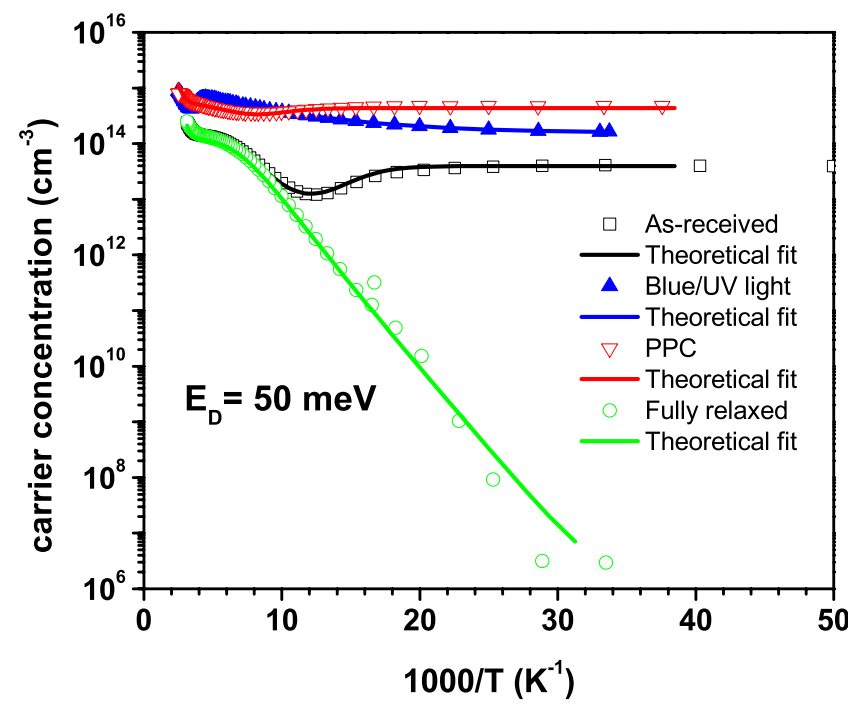

FIG. 1. (Color online) Arrhenius plot of measured carrier concentration and two-layer model fits for hydrothermal $\mathrm{ZnO}$ : (i) as received; (ii) under blue/UV illumination (not all points are shown for clarity); (iii) showing PPC immediately following irradiation; (iv) after relaxation of PPC and exposure to air.

\section{RESULTS AND DISCUSSION}

Temperature dependences of the carrier concentration $n$ and Hall mobility $\mu_{H}$ for the series of experiments described above are shown in Figs. 1 and 2, respectively. For the asreceived sample, the curves can be separated into three distinct regions: (i) low temperature $(T<60 \mathrm{~K})$ where conduction in the surface layer dominates (carriers in the bulk are frozen out $\left.{ }^{19}\right)$, (ii) high temperature $(T>100 \mathrm{~K})$ where bulk conduction is dominant, and (iii) an intermediate temperature range $(60 \mathrm{~K}<T<100 \mathrm{~K})$ where both the surface layer and bulk region contribute significantly to the total conduction. At low $T$, the carrier concentration in the surface region is nearly independent of temperature (degenerate) and the mobility is very low $\left(\mu_{H}<30 \mathrm{~cm}^{2} / \mathrm{V} \mathrm{s}\right)$. In the high $T$ region, two bulk donor levels, at 50 and $400 \mathrm{meV}$, are observed and the mobility at $294 \mathrm{~K}$ is $\mu_{H}=187 \mathrm{~cm}^{2} / \mathrm{V}$ s. It should be noted that the carrier concentration data in Fig. 1 are presented as volume concentrations $\left(\mathrm{cm}^{-3}\right)$, which assume uniform conduction throughout the sample volume, since Hall effect only measures a sheet concentration. Clearly, this is not the case for conduction in a surface layer. Fortunately, since the surface layer is degenerate, it is possible to separate the contributions to the conduction from the surface and bulk

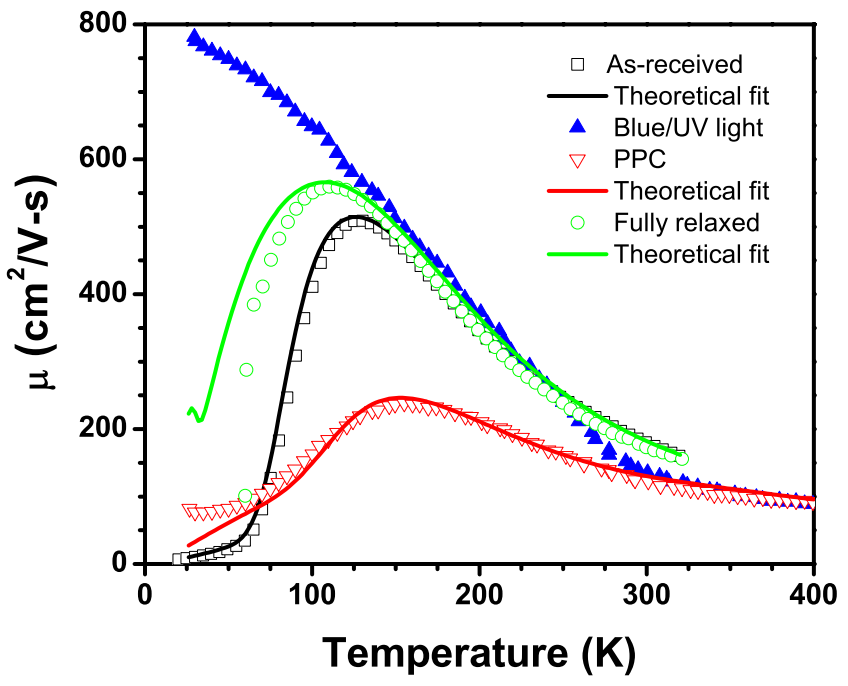

FIG. 2. (Color online) Measured temperature dependence of Hall mobility and two-layer model fits for hydrothermal $\mathrm{ZnO}$ : (i) as received; (ii) under blue/UV illumination (not all points are shown for clarity); (iii) showing PPC immediately following irradiation; (iv) after relaxation of PPC and exposure to air.

regions and analyze the data using a two-layer Hall-effect model. ${ }^{14,17}$ From this analysis, a minimum thickness for the surface layer can be estimated. ${ }^{14}$ Simultaneous theoretical fits of both $n$ and $\mu_{H}$ using the two-layer model are shown in Figs. 1 and 2, and the best-fit parameters are summarized in Table I.

Illumination by blue/UV light produces significant changes in the temperature dependences of $n$ and $\mu_{H}$, as seen in Figs. 1 and 2. Over most of the temperature range, conduction is dominated by the surface layer or the combination of surface layer and bulk. The measured carrier concentration is about one order of magnitude larger than that measured in the as-received sample. Thermal activation from the $50 \mathrm{meV}$ bulk donor level is no longer observed, but activation from the $400 \mathrm{meV}$ bulk donor still begins to appear at the highest measurement temperatures. The most significant change in the temperature dependence of $\mu_{H}$ compared to the as-received sample occurs for $T<120 \mathrm{~K}$. Trapping of photocarriers by donors and acceptors leaves most of these impurities in a neutral electronic state. As a result, ionized impurity scattering, which usually limits the carrier mobility at low $T$, is reduced dramatically, and $\mu_{H}$ decreases monotonically with temperature. Because of this nonthermal distribution of carriers under illumination, theoretical analysis using

TABLE I. Best-fit two-layer Hall-effect model parameters for bulk and surface donor and acceptor concentrations.

\begin{tabular}{lccccc}
\hline \hline Sample & $\begin{array}{c}N_{D}(50 \mathrm{meV}) \\
\left(10^{16} \mathrm{~cm}^{-3}\right)\end{array}$ & $\begin{array}{c}N_{D}(400 \mathrm{meV}) \\
\left(10^{16} \mathrm{~cm}^{-3}\right)\end{array}$ & $\begin{array}{c}N_{A} \\
\left(10^{16} \mathrm{~cm}^{-3}\right)\end{array}$ & $\begin{array}{c}d_{\text {surf,min }} \\
(\mathrm{nm})\end{array}$ & $\begin{array}{c}N_{D \text { surf,min }} \\
\left(10^{16} \mathrm{~cm}^{-3}\right)\end{array}$ \\
\hline As received & 1.228 & 1.5 & 1.215 & 1.5 & 1400 \\
PPC & 1.228 & 1.5 & 1.215 & 38 & 610 \\
After photo-Hall & 2.0 & 2.0 & 1.98 & N/A & N/A \\
Forming gas anneal & 2.0 & 2.0 & 1.2 & N/A & N/A \\
\hline \hline
\end{tabular}


the two-layer model is not applicable. However, when measurement of the temperature-dependent Hall effect is repeated in the dark, immediately following the photo-Hall experiment, this limitation on the two-layer analysis is removed. The experimental and theoretical curves for this case are shown in Figs. 1 and 2, and the resulting model parameters are listed in Table I. There is little change in the temperature dependence of $n$ when the light is removed, indicating the presence of strong PPC in the sample. However, $\mu_{H}$ is substantially lower than that in either the illuminated or as-received sample ( $\sim 2.5$ times lower peak mobility), except for the low $T$ region dominated by the surface layer $\left(\mu_{H}\right.$ $<90 \mathrm{~cm}^{2} / \mathrm{V} \mathrm{s}$ ). According to the two-layer model fit (see Table I), the minimum thickness of the surface layer has increased by $\sim 25$ times as a result of the blue/UV illumination, so it seems reasonable that surface scattering would be reduced for carriers that are farther away from the surface.

The decay of PPC in this sample while in vacuum was very slow, similar to previous observations ${ }^{11,13}$ in other $\mathrm{ZnO}$ samples. Temperature dependences of $n$ and $\mu_{H}$ after the PPC was allowed to relax fully and the sample was exposed to air are shown in Figs. 1 and 2. Here, the sample characteristics are similar to those in the as-received sample in the high $T$ region, but in the low and intermediate $T$ regions the sample behaves very differently. The bulk 50 and $400 \mathrm{meV}$ donors are still apparent at high $T$, but at low and intermediate temperatures the conduction is now controlled by the $50 \mathrm{meV}$ donor over five orders of magnitude, down to $n$ $\sim 3.0 \times 10^{8} \mathrm{~cm}^{-3}$, and there is no indication of any surface conduction. This volume concentration corresponds to a limit in the maximum possible value the surface sheet carrier density could have of $n_{\mathrm{sh} \text {,max }} \sim 1.6 \times 10^{7} \mathrm{~cm}^{-2}$. This represents the lowest surface concentration for any $\mathrm{ZnO}$ sample that we have ever measured. Additionally, this low value for $n_{\text {sh,max }}$ indicates that no significant surface segregation of group III impurities, such as $\mathrm{Al}, \mathrm{Ga}$, or In, has occurred as has been observed $^{15}$ recently in thermally annealed samples. It is interesting to note that the two-layer model fit of the PPCrelaxed sample shows an increase in the concentrations of both the 50 and $400 \mathrm{meV}$ donors as well as the acceptor concentration as compared to the as-received sample (see Table I). These fits also indicate that in both the as-received and the PPC-relaxed states the compensation ratio in the sample is very nearly unity. Taken together, the results from this series of experiments make it clear that irradiation with blue/UV light in vacuum at moderate temperatures can be very effective at cleaning the surface of $\mathrm{ZnO}$ and reducing the conductive surface layer which nearly all commercial $\mathrm{ZnO}$ samples exhibit. ${ }^{19,20}$

The absence of a surface conducting layer in the sample following blue/UV illumination in vacuum provides a unique opportunity to investigate the effect of $\mathrm{H}$ on the electrical properties of $\mathrm{ZnO}$. It was originally suggested ${ }^{21,22}$ that interstitial $\mathrm{H}$ could function as a shallow donor in $\mathrm{ZnO}$ but that model has since been revised ${ }^{23}$ to propose that substitutional $\mathrm{H}$ serves as a shallow donor. Annealing $\mathrm{ZnO}$ at $600{ }^{\circ} \mathrm{C}$ in $\mathrm{N}_{2}$ is known ${ }^{24}$ to remove $\mathrm{H}$ from the sample so it is a reasonable

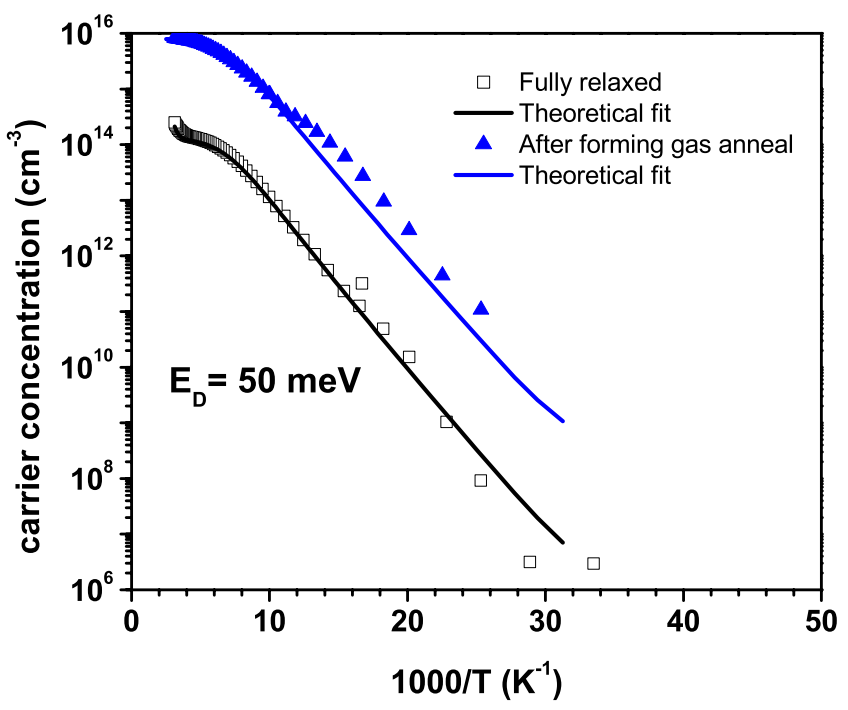

FIG. 3. (Color online) Increase in bulk carrier concentration for UV-cleaned sample following $30 \mathrm{~min}$ anneal at $600{ }^{\circ} \mathrm{C}$ in forming gas.

assumption that $\mathrm{H}$ from the forming gas would enter the sample easily at this temperature. Figure 3 shows the changes in carrier concentration for the UV-"cleaned" sample that result from a 30 min anneal in forming gas at $600{ }^{\circ} \mathrm{C}$. The principal effect of the forming gas anneal is a 100 times increase in the carrier concentration at all temperatures. The $50 \mathrm{meV}$ donor level still controls the carrier concentration over a range of five orders of magnitude, but thermal activation of the $400 \mathrm{meV}$ donor is no longer seen at high $T$, most likely because it is overwhelmed by the shallower level. There is still no indication of any surface conduction and no new donor levels are found. The two-layer Hall-effect model fit shows no change in the concentration of either the 50 or $400 \mathrm{meV}$ level but shows a $40 \%$ reduction in the concentration of acceptors (see Table I). This result indicates that $\mathrm{H}$ most likely plays an important role of passivating acceptors in $\mathrm{ZnO}$ and confirms that interstitial $\mathrm{H}$ is not a dominant shallow donor.

\section{CONCLUSIONS}

We have demonstrated permanent changes in the surface conducting layer found in as-received hydrothermal $\mathrm{ZnO}$ by irradiation with blue/UV light in vacuum at $T<400 \mathrm{~K}$. An upper limit is determined for the surface sheet carrier concentration, $n_{\mathrm{sh}, \max }<1.6 \times 10^{7} \mathrm{~cm}^{-2}$, following irradiation, which is the lowest concentration we have ever observed. Subsequent annealing in forming gas increases the bulk carrier concentration but does not increase existing donor concentrations or introduce new donor levels. However, the forming gas anneal reduces the bulk acceptor concentration by $40 \%$, most likely through $\mathrm{H}$ passivation.

\section{ACKNOWLEDGMENTS}

The authors would like to thank T. A. Cooper for Halleffect measurements. Support is gratefully acknowledged from the following sources: AFOSR Grant No. FA9550-07- 
1-0013 (K. Reinhardt), NSF Grant No. DMR0513968 (L. Hess), DOE Grant No. DE-FG02-07ER46389 (R. Kortan), ARO Grant No. W91NF-07-D-0001/Task07275 (M. Gerhold), and AFRL Contract No. FA8650-06-D-5401 (S. Shell and D. Silversmith).

${ }^{1}$ G. Heiland, E. Mollwo, and F. Stockmann, Solid State Phys. 8, 191 (1959).

${ }^{2}$ J. J. Lander, J. Phys. Chem. Solids 14, 137 (1960).

${ }^{3}$ G. Heiland and P. Kunstmann, Surf. Sci. 13, 72 (1969).

${ }^{4}$ G. Heiland, Sens. Actuators 2, 343 (1982).

${ }^{5}$ D. C. Look, Mater. Sci. Eng., B 80, 383 (2001).

${ }^{6}$ U. Ozgur et al., J. Appl. Phys. 98, 041301 (2005).

${ }^{7}$ S. J. Pearton, D. P. Norton, K. Ip, Y. W. Heo, and T. Steiner, Prog. Mater. Sci. 50, 293 (2005).

${ }^{8}$ G. Heiland and D. Kohl, Phys. Status Solidi A 49, 27 (1978).

${ }^{9}$ G. Heiland, J. Phys. Chem. Solids 22, 227 (1961).

${ }^{10}$ H. Moormann, D. Kohl, and G. Heiland, Surf. Sci. 100, 302 (1980).

${ }^{11}$ B. Claflin, D. C. Look, and D. R. Norton, J. Electron. Mater. 36, 442
(2007).

${ }^{12}$ G. Heiland, E. Mollwo, and F. Stockmann, in Solid State Physics, edited by F. Seitz and D. Turnbull (Academic, New York, 1959), Vol. 8, p. 191.

${ }^{13}$ B. Claflin, D. C. Look, S. J. Park, and G. Cantwell, J. Cryst. Growth 287, 16 (2006).

${ }^{14}$ D. C. Look, J. Appl. Phys. 104, 063718 (2008).

${ }^{15}$ D. C. Look, B. Claflin, and H. E. Smith, Appl. Phys. Lett. 92, 122108 (2008).

${ }^{16}$ O. Schmidt, P. Kiesel, D. Ehrentraut, T. Fukuda, and N. M. Johnson, Appl. Phys. A: Mater. Sci. Process. 88, 71 (2007).

${ }^{17}$ D. C. Look, Surf. Sci. 601, 5315 (2007).

${ }^{18}$ Tokyo Denpa Co., Ltd., 5-6-11 Chuo, Ohta-ku, Tokyo 1430024, Japan.

${ }^{19}$ D. C. Look, H. L. Mosbacker, Y. M. Strzhemechny, and L. J. Brillson, Superlattices Microstruct. 38, 406 (2005).

${ }^{20}$ O. Schmidt, P. Kiesel, C. G. Van de Walle, N. M. Johnson, J. Nause, and G. H. Dohler, Jpn. J. Appl. Phys., Part 1 44, 7271 (2005).

${ }^{21}$ C. G. Van de Walle, Phys. Rev. Lett. 85, 1012 (2000).

${ }^{22}$ C. G. Van de Walle, Phys. Status Solidi B 235, 89 (2003).

${ }^{23}$ A. Janotti and C. G. Van de Walle, Nature Mater. 6, 44 (2007).

${ }^{24}$ N. Nickel and K. Fleischer, Phys. Rev. Lett. 90, 197402 (2003). 